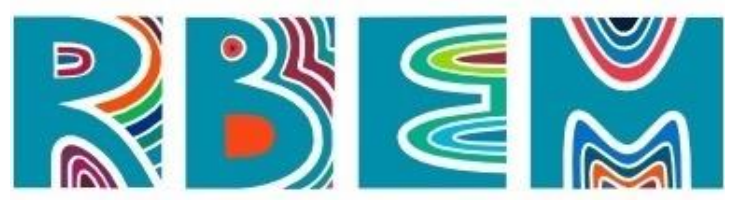

REVISTA BAIANA DE EDUCAÇÃO MATEMÁtICA

\title{
ARTIGO
}

do] https://doi.org/10.47207/rbem.v2i01.12502

\section{TRIGONOMETRIZANDO NA ROÇA: implicações de uma educação matemática contextualizada}

\author{
MOTA, Charles Maycon de Almerida \\ Universidade do Estado da Bahia - Doutorando em Educação e Contemporaneidade. ORCID: \\ http://orcid.org/0000-0001-5927-3466. E-mail: charlesmaycon22@hotmail.com
}

\section{SILVA, Fabrício Oliveira da Silva}

Universidade Estadual de Feira de Santana - UEFS. Pós- Doutor e Doutor em Educação e Contemporaneidade. ORCID http://orcid.org/0000-0002-7962-7222. E-mail: fosilva@uefs.br.

\begin{abstract}
Resumo: O presente texto busca compreender como as experiências com oficinas pedagógicas de ensino de matemática em espaço rural favoreceu o ensino e aprendizagem da geometria por licenciandos de Pedagogia e por estudantes do ensino fundamental. O texto reflete os contextos da roça, evidenciando como isso pode ser potencializado como lócus para valorização de fazeres na docência que extrapolem os muros da escola e se ampliem pelos contextos de vida de seus estudantes. Compõe a metodologia deste trabalho a realização de uma oficina pedagógica com carga horária de 12h, realizada no Sítio Mata da Lua por licenciandas do Curso de Pedagogia na disciplina Ensino da Matemática, ministrada para estudantes do $9^{\circ}$ Ano do Ensino Fundamental II e das três séries do Ensino Médio. A oficina foi o dispositivo de pesquisa utilizado por possibilitar reflexões acerca do desenvolvimento de práticas docentes que com vistas a tematizar e valorizar o contexto dos alunos através de um estudo sobre os conceitos de trigonometria, geometria plana e medidas de superfícies em situações e vivências na roça. Tomamos os relatos de professoras e estudantes que participaram dessa oficina como elemento de análise. Conclui-se que o ensino de matemática gera significações para o estudante quando o contexto em que ele vive é levado em consideração para a construção de saberes escolares. A roça foi entendida como um lócus de atuação da docência em matemática, possibilitando que os estudantes criassem relações entre saberes da roça com os da trigonometria, numa construção de aprendizagens significativas sobre os saberes matemáticos.
\end{abstract}

Palavras-chave: Ensino da Matemática. Formação Inicial. Educação contextualizada. Docência na roça.

\section{Trigonometry in rural space: implications of contextualized mathematics education}

\begin{abstract}
This text seeks to understand how the experiences with pedagogical workshops teaching mathematics in rural areas favored the teaching and learning of geometry by undergraduate Pedagogy and by elementary school students. The text reflects the contexts of the farm, showing how this can be enhanced as a locus for valuing actions in teaching that go beyond the school walls and expand by the contexts of their students' lives. The methodology of this work comprises the realization of a
\end{abstract}




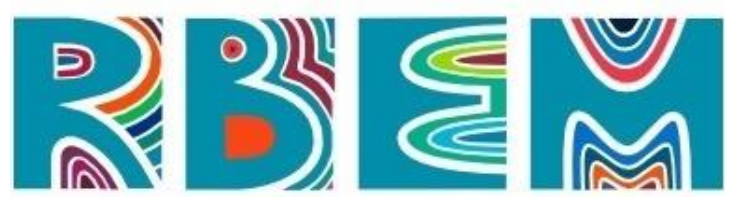

REVISTA BAIANA DE EDUCAÇÃO MATEMÁTICA

pedagogical workshop with a workload of 12 hours, held at Sítio Mata da Lua by graduates of the Pedagogy Course in the Teaching of Mathematics discipline, given to students of the 9th grade of Elementary School II and of the three grades of the High school. The workshop was the research device used to enable reflections on the development of teaching practices that aim to theorize and value the students' context through a study on the concepts of trigonometry, plane geometry and surface measurements in situations and experiences in the fields. We take the reports of teachers and students who participated in this workshop as an element of analysis. It is concluded that the teaching of mathematics generates meanings for the student when the context in which he lives is taken into consideration for the construction of school knowledge. The garden was understood as a locus of teaching in mathematics, enabling students to create relationships between knowledge of the field and those of trigonometry, in a construction of significant learning about mathematical knowledge.

Keywords: Mathematics teaching. Initial formation. Contextualized education. Teaching in the country.

\section{Trigonometrizando en el espacio rural: implicaciones de la educación matemática contextualizada}

Resumen: Este texto busca comprender cómo las experiencias con talleres pedagógicos de enseñanza de la matemática en áreas rurales favorecieron la enseñanza y el aprendizaje de la geometría por parte de los estudiantes de pregrado de Pedagogía y de la escuela primaria. El texto refleja los contextos del espacio rural, mostrando cómo estes se pueden potenciar como un locus para valorar acciones en la enseñanza que van más allá de los muros de la escuela y se expanden por los contextos de la vida de sus alumnos. La metodología de este trabajo comprende la realización de un taller pedagógico con una carga de trabajo de 12 horas, realizado en el Sítio Mata da Lua por estudiantes del Curso de Pedagogía en la disciplina de Enseñanza de las Matemáticas, impartido a alumnos del $9^{\circ}$ grado de la Escuela Primaria II y de los tres grados de la Escuela secundaria. El taller fue el dispositivo de investigación utilizado para posibilitar reflexiones sobre el desarrollo de prácticas docentes, con la intención de tematizar y valorar el contexto de los estudiantes a través de un estudio sobre los conceptos de trigonometría, geometría plana y medidas de superficie en situaciones y experiencias de campo. Tomamos los informes de profesores y alumnos que participaron en este taller como elemento de análisis. Se concluye que la enseñanza de las matemáticas genera significados para el alumno cuando se toma en consideración el contexto en el que vive para la construcción del conocimiento escolar. El espacio rural fue entendido como un locus de enseñanza en matemáticas, que permite a los estudiantes crear relaciones entre los conocimientos del campo y los de la trigonometría, en una construcción de aprendizajes significativos sobre el conocimiento matemático.

Palabras clave: Enseñanza de las matemáticas. Formación inicial. Educación contextualizada. Docencia en el campo.

\section{Introdução}

No cenário educacional contemporâneo tem sido uma recorrência enveredar por discussões que considerem um ensino e a aprendizagem como processos que se transversalizam por uma educação contextualizada. Em se tratando da educação matemática evidencia-se uma necessidade de que o ensino se concretize em perspectivas inovadoras, que 


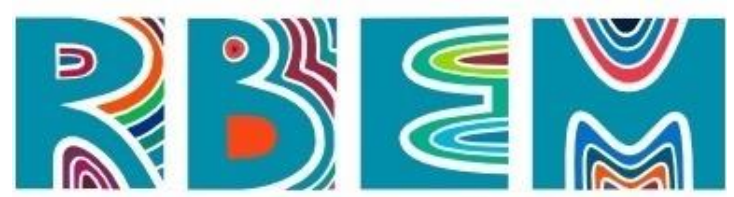

REVISTA BAIANA DE EDUCAÇÃO MATEMÁTICA

segundo Alves e Cavalcante (2017) ganham notoriedade no campo da educação matemática quando os professores consideram o contexto de aprendizagem e as reais necessidades dos aprendentes. Nessa direção, a ideia de ensino implica numa dimensão de se considerar os contextos em que a aprendizagem deve acontecer. Trata-se, portanto de contextos que possibilitem compreensões e atribuição de significados para aquilo que se aprende, o que se assenta numa ideia de inovação filiada à compreensão do fazer contextualizado.

Ainda segundo os estudos desenvolvidos por Alves e Cavalcante (2017) tem sido bastante necessário o fato de educadores buscarem desenvolver práticas de ensino que possibilitem uma aprendizagem que também seja ancorada nas perspectivas da inovação, entendida como basilar na construção de elementos facilitadores da prática docente, tendo em vista contextualizar o ensino e pensar a valorização dos espaços de vida e de como estes espaços podem ser tomados como lugares de aprendizagem, possibilitando que o estudante, a partir disso, inove nos processos de compreensão e de desenvolvimento de aprendizagens. É nessa linha de pensamento que o presente trabalho traz para a cena as reflexões em torno de se defender uma educação contextualizada, que leve em consideração a produção de saberes oriundos das aprendizagens experienciais tecidas no cotidiano escolar.

A ideia de cotidiano evoca nesse trabalho a transcendência do espaço escolar, para além do muro da escola, buscando ampliar o sentido de escola para outros espaços formativos no ensino de matemática, como é o caso da roça, que se insurge como um espaço possibilitador de que o ensino se concretize em princípios de inovação, bem como de contextualização de práticas que se efetivam pela ancoragem de saberes que portam os estudantes por vivenciarem a roça em seus cotidianos. Nessa lógica, a roça é um espaço educativo produtor de saberes, a partir dos quais os estudantes desenvolvem outros saberes matemáticos, ancorando estes nos que já possuem vivências e compreensões. Tal ideia se sustenta nas perspectivas da aprendizagem significativa, que segundo Ausubel (1982) é aquela para a qual o aprendiz atribui significado por partir de algo que já conhece, elementos de ancoragem, para construir novos saberes, e nisso desenvolver aprendizagem que tenha sentido para si, que emerja da condição de aprender e, por isso, valorizar aquilo que se aprende.

É nessa direção, também, que a educação matemática se efetiva numa tecitura das produções de táticas e astúcias que desenvolvem os discentes para aprenderem a matemática. 


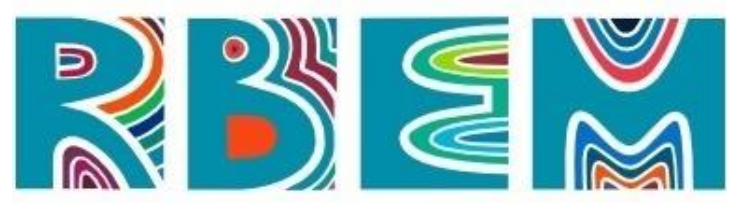

REVISTA BAIANA DE EDUCAÇÃO MATEMÁTICA

Trata-se de buscar na escola desenvolver ações que possibilitem ao próprio estudante lidar com os processos de aprendizagem. Isso implica num reconhecimento de que o cotidiano é inventado pelos estudantes, para sobrevivência na fábrica da aprendizagem, que gera as condições para que eles próprios produzam suas táticas para aprender matemática e perceber que podem aplicar os conhecimentos da área em seus contextos de vida na roça ${ }^{\mathrm{i}}$. Nessa lógica é possível perceber como os contextos de aprendizagem geram possibilidades para que a aprendizagem transcorra, em matemática, por vias que se espelha, na invenção do cotidiano de Certeau (1994), ao considerar o que o sistema capitalista precisa ser entendido para gerar condições de que o homem aí produza suas artimanhas e modos de viver em tal sistema.

Algo parecido se dá na escola quando os estudantes precisam aprender a matemática, criando por meio dela, táticas e astúcias para significar aquilo que aprendem, num determinado contexto vivencial e experiencial. É daí, também, que as ideias de vivências e experiências, enquanto acontecimentos que tocam, marcam, transformam o sujeito aprendente, são basilares e corroboram para que haja protagonismo do aluno, nos modos próprios que cada um vai encontrando para construir suas maneiras de estudar e aprender matemática na escola, que se amplia nesse trabalho para o espaço da roça. A escola é a roça, é a vida do aprendiz que é ressignificada, tanto por professores em formação inicial para a docência, como também ressignificada por cada estudante da escola básica, residente nas comunidades rurais, que buscam em suas próprias experiências aprender matemática.

Nessa seara, o presente trabalho se constitui numa pesquisa que se desenvolveu por meio da realização de uma oficina proposta na disciplina Ensino da Matemática desenvolvida por graduandos do curso de Pedagogia da Faculdade Regional de Riachão do Jacuípe - FARJ, no Pólo de Várzea do Poço - BA. A centralidade desta proposta está na reflexão a partir da experiência com o desenvolvimento de práticas docentes em espaços não formais com o intuito de vivenciar os processos de planejamento e avaliação referentes à área da Matemática, utilizando a contextualização de conteúdos para possibilitar aos estudantes, que moram em áreas rurais, uma experiência que desencadeie o desenvolvimento de uma aprendizagem significativa.

A questão que mobilizou o presente estudo foi construída pelas próprias licenciandas, executoras das oficinas, quando se questionaram: Como o ensino de trigonometria pode gerar sentidos para estudantes da roça se tecido na própria roça? De que maneira os conhecimentos 


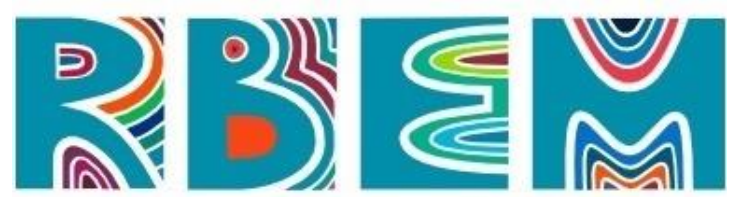

REVISTA BAIANA DE EDUCAÇÃO MATEMÁTICA

prévios dos estudantes possibilitarão compreensões dos conceitos da geometria? Como o ensino de matemática contextualizado pelo cotidiano da roça pode favorecer uma aprendizagem também contextualizada?

Ancorados nessas questões, o texto objetivou compreender como as experiências com oficinas pedagógicas de ensino de matemática em espaço rural favoreceu aprendizagem da geometria por estudantes do ensino fundamental.

O texto está dividido em quatro sessões, mais essa introdução. Assim sendo, na seção a seguir, apresentamos as tecituras metodológicas das oficinas, evidenciando os sujeitos, os cenários e o modo operativo em que o estudo foi constituído. Na segunda seção, abordamos uma discussão sobre a educação contextualizada no município de Várzea do poço, lócus do sítio em que se desenvolveu o presente estudo, discorrendo sobre os princípios de uma educação que se tece nas táticas e astúcias do cotidiano escolar, com foco nas estratégias que estudantes e professores em formação inicial desenvolvem para ensinar e aprender. $\mathrm{Na}$ terceira sessão, apresentamos os resultados, evidenciando os achados da pesquisa nas teias das discussões sobre cotidiano escolar e das aprendizagens significativas, tecendo aspectos da iniciação à docência, balizadas pela política de formação experiencial em aderência às situações de uma educação contextualizada. Por fim, mas não menos importante, tecemos as

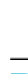
considerações finais.

\section{Trilha metodológica}

A tecitura metodológica do presente estudo se deu a partir do dispositivo oficina pedagógica. Assim sendo, a oficina foi utilizada por favorecer o desenvolvimento prático do processo de ensino e de aprendizagem da geometria, num contexto real da roça, logo cotidiano e dinâmico para a vida dos estudantes.

A oficina foi realizada no Sítio Mata da Lua ${ }^{\mathrm{ii}}$ com o objetivo de refletir sobre o desenvolvimento de práticas docentes que valorizem o contexto dos alunos através de um estudo sobre os conceitos de trigonometria, geometria plana e medidas de superfícies em situações e vivências na roça. Portanto, este trabalho foi desenvolvido com licenciandas do curso de Pedagogia na disciplina Ensino da Matemática, em que tais graduandos convidariam 


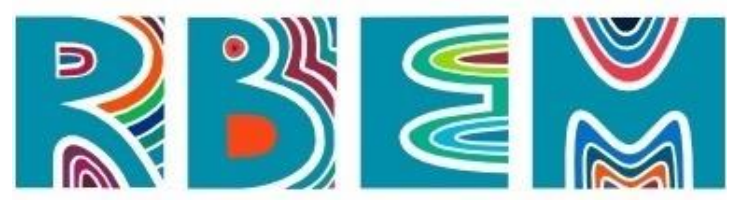

REVISTA BAIANA DE EDUCAÇÃO MATEMÁTICA

estudantes que estão ligados a espaços de educação não formal em espaços rurais do município de Várzea do Poço - BA.

Os estudantes que participaram da oficina estavam matriculados em escolas situadas na sede do município e cursavam o $9^{\circ}$ ano do Fundamental II, $1^{\circ}, 2^{\circ}$ e $3^{\circ}$ anos do Ensino Médio, numa faixa etária de 14 a 19 anos, moradores de localidades rurais que diariamente fazem o percurso para acessarem as escolas da cidade. Esclarecemos, que por questões de ética em pesquisa, os nomes dos colaboradores são fictícios.

Vale mencionar que a oficina foi realizada no período de $12 \mathrm{~h}$ de envolvimento entre mediadores e estudantes, sendo organizada por momentos planejados entre socialização de discussões, exploração do potencial pedagógico do sítio, realização de atividades práticas e algumas listas de exercícios criados a partir de situações vivenciadas no próprio espaço rural.

No primeiro momento, fizemos uma mística que se utilizou de sementes, frutos e elementos existentes na roça para uma reflexão sobre o surgimento da matemática, numa contextualização da história da matemática, de modo que os estudantes fossem apresentando seus conhecimentos a respeito de seu espaço de vida e daquilo que consideram saber matemático a partir do que vivenciam na roça. Este foi um momento de entrosamento entre os estudantes, já que são de turmas diferentes, bem como interação com as mediadoras da oficina. Tal dinâmica favoreceu a ideia de que quando há uma proposição pedagógica que toma os contextos de vida e seus elementos como ponto inicial para a construção de novos conhecimentos, somos provocados a construção de aprendizagens significativas.

No segundo momento, foi realizada uma visita ao espaço do sítio, explorando todos os lugares em que podíamos realizar demonstrações de situações em que se poderia visibilizar a trigonometria. Nessa lógica, foram realizados cálculos e medidas para encontrar o valor correspondente à altura de árvores e troncos velhos em meio à mata a partir de sua sombra ou parte caída que ainda estava presa ao solo, numa simulação triangular. Utilizamos cancelas, telhados de baias e curral, fizemos simulações com cordas e tornos no chão para formar triângulos, encontrar valores de hipotenusa e catetos.

No terceiro momento, nos reunimos no varandado da casa no sítio e passamos a discutir sobre os conceitos da trigonometria, dirimindo dúvidas e auxiliando nas dificuldades do que os estudantes ainda apresentavam. Esse foi o momento em que realizamos listas de exercícios a partir das simulações que foram feitas nos espaços do sítio, como uma maneira de 


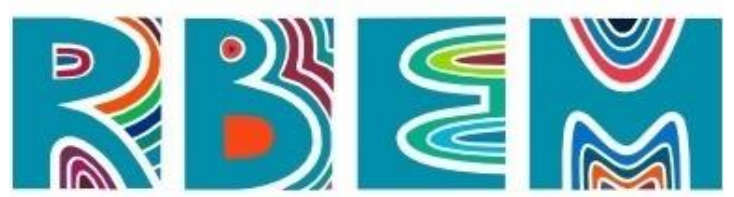

REVISTA BAIANA DE EDUCAÇÃO MATEMÁTICA

aprimorar os conhecimentos apresentados e aplicar fórmulas de conceitos da matemática. Esse momento culminou com a mini gincana para avaliar todo o processo proposto na oficina. Foi o momento em que se visibilizaram as táticas e as astúcias de cada estudantes a produzirem resultados dos exercícios, utilizando o conhecimento do cotidiano. Foi também momento para que as licenciandas percebessem a construção de diferentes estratégias de ensino e reflexão desse para a produção de aprendizagens da matemática.

No decorrer desses momentos, aproveitamos para colher alguns relatos sobre o movimento formativo que ia se dando no contexto da oficina. Tais relatos se constituíram aqui, também, como elementos de análise para compreensão sobre como o ensino de trigonometria pode gerar sentidos para estudantes da roça se tecido na própria roça, bem como, ressignificar os conhecimentos que esses estudantes tinham sobre seus contextos de vida, gerando aprendizagens significativas.

As oficinas tiveram uma tecitura reflexiva ancorada num movimento de pensar caminhos para as professoras em formação inicial como busca de formas próprias que possibilitassem o desenvolvimento de ações docentes. Com o trigonometrizando na roça, as ações pedagógicas ancoraram-se num paradigma de compreensão do ensino contextual, tecido a partir da lógica de entendimento e uso de táticas dos estudantes face ao conhecimento da roça, logo ao conhecimento cotidiano de suas vidas. Assim, a concepção de prática docente ancorou-se na compreensão do ensino de matemática centrado numa proposta de educação contextualizada como possibilidade de uma potencialização dos conhecimentos prévios que alunos oriundos da roça trazem consigo.

Propor um espaço de formação que se colocasse como lugar de insurgência no sentido de romper lógicas urbanocêntricas, valorizando a roça, saberes, vivências e experiências que estudantes oriundos da roça produziram ao longo de suas existências se apresenta aqui como potência formativa para pensar o ensino de matemática com base nos princípios de uma educação contextualizada. Além disso, se coloca como provocação de uma formação que considera as táticas e astúcias contributos reconfiguradores dos contextos da docência na contemporaneidade.

Este trabalho teve como proposição inicial a discussão sobre os conceitos de Trigonometria e seus elementos que foi compreendendo a retomada de outros conteúdos da Matemática a partir de uma dinâmica que envolvia os elementos encontrados na mata e em 


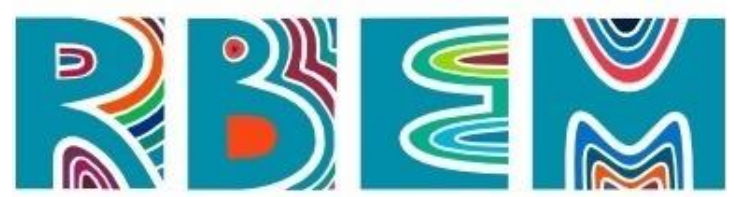

REVISTA BAIANA DE EDUCAÇÃO MATEMÁTICA

torno do sítio e que serviram para uma retomada sobre a história da matemática e fundamentação de que tal área foi e sempre será útil para o avanço da ciência e a evolução da humanidade.

Logo após a apresentação sobre os conceitos e compreensão das fórmulas que seriam utilizadas no decorrer das experimentações práticas foi apresentado o espaço do sítio onde poderíamos utilizar exemplos e situações relacionadas aos conteúdos que seriam abordados, neste momento se propunha que os estudantes anotassem as dúvidas e/ou criassem novas situações-problema, seguindo com as mesmas temáticas, foram expostas algumas outras situações que exploravam a geometria plana e tridimensional em várias localidades do sítio.

Após todas as experimentações dividiu-se os estudantes por equipe para a realização de uma mini gincana como forma de avaliar o processo de ensino e aprendizagem através dessa proposição didática, onde faríamos as correções de todas as questões apresentadas no final da tarde como uma revisão de todo o conteúdo abordado.

Dessa maneira, propusemos também, uma avaliação da oficina a ser realizada pelos participantes, mas como o tempo ficou curto para a exploração de tantas situações, foi sugerido que aqueles que se sentissem à vontade fizesse a exposição de suas impressões sobre o momento, alguns alunos se posicionaram e emitiram essas impressões de modo que valorizou o projeto, enfatizando como a sua aprendizagem acontecera. Mas como a tecnologia esteve presente durante todo o nosso trabalho, onde esses mesmos estudantes sempre estavam fotografando sua participação e postando nas redes sociais, fomos surpreendidos por uma situação de avaliação do projeto e sua metodologia em rede.

São muitas as discussões a respeito de práticas pedagógicas que propõem metodologias de ensino que possibilitem o desenvolvimento de uma aprendizagem significativa na área de Matemática, tais discussões tem nos feito refletir a respeito das competências e habilidades que o currículo desta área requer de nossos estudantes, desse modo, podemos notar que é necessário reformular as propostas curriculares e pedagógicas nas escolas, de modo, a atender às diversas realidades que cada instituição escolar está inserida, pois devemos considerar as possibilidades necessárias que um indivíduo precisa para fazer relações entre seus conhecimentos prévios e o conhecimento que lhe é apresentado com o intuito de construir um novo conhecimento, assim podemos enfatizar o pensamento a partir do método dialético (MORETTO, 2007). 


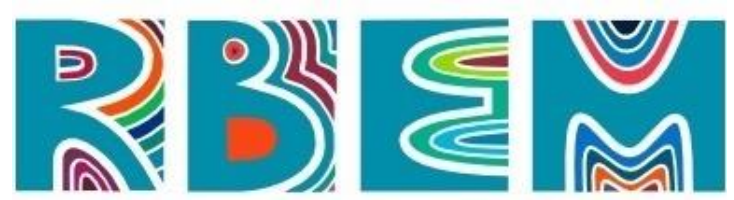

REVISTA BAIANA DE EDUCAÇÃO MATEMÁTICA

É importante enfatizar que, em decorrer dessas discussões mencionadas anteriormente, já se tem alguns avanços que vem contribuir fortemente com as desmistificações sobre esta área do conhecimento, neste sentido, podemos mencionar as políticas públicas para a formação inicial e continuada para professores de matemática, a exemplo do curso do Próletramento em Matemática que:

prevê a utilização do princípio da problematização dos conteúdos e das práticas cotidianas dos professores para o ensino da matemática. Busca significar práticas e conteúdos sem perder a cientificidade necessária à vida do cidadão, trazendo à tona novas leituras com novos enfoques para o ensino da matemática (BRASIL, 2007, p. 9).

Não podemos deixar de mencionar a contribuição das feiras Baianas de Matemática que vem possibilitando uma nova reflexão sobre um fazer pedagógico diferenciado, que nos oferecesse condições para contemplarmos diversas práticas de ensino que se pautam na contextualização, dando ênfase aos produtos construídos a partir da associação entre os elementos do mundo vivido e os elementos do mundo sistêmico.

Essas duas iniciativas tem sido considerável para que nossas práticas de ensino valorizem uma educação contextualizada, propondo uma nova reconfiguração no processo de ensinar e aprender matemática.

\section{Caracterização do município e sua proposta de educação contextualizada}

Considerando que Várzea do Poço - BA é caracterizada como um município rural, estando situada a $330 \mathrm{~km}$ da capital, tendo uma área territorial de $220 \mathrm{~km}^{2}$, uma população de 8.600 habitantes, sua economia está fortemente baseada na agricultura familiar e na pecuária, sua proposta educacional se baseia nas teorias de Paulo Freire para fundamentar a metodologia de educação contextualizada a partir do Projeto "A educação que a gente quer, do jeito que a gente é" - uma iniciativa da Diocese de Rui Barbosa implantada no município no ano de 2003 nas escolas do campo e se expandiu por todos os níveis da educação básica no município.

Partindo da premissa de que é necessário valorizarmos os diversos locais de vivência, bem como, as práticas cotidianas de trabalho e lazer, das pessoas que convivem no polígono 


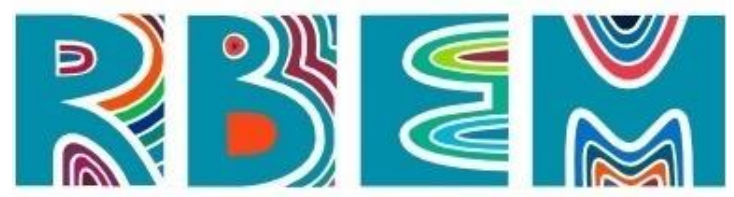

REVISTA BAIANA DE EDUCAÇÃO MATEMÁTICA

da seca, surgem como problemática a aplicabilidade de conteúdos que compõem o currículo formal no cotidiano dos estudantes do $9^{\circ}$ Ano do Ensino Fundamental ao $3^{\circ}$ ano do Ensino Médio que moram em áreas rurais do município. Desse modo, propôs-se desenvolver uma oficina de estudo para se discutir sobre Trigonometria e Geometria, pressupondo a orientação para a utilização dos conceitos matemáticos sobre esses conteúdos e sua aplicação nas atividades que muitos desses estudantes já desenvolvem em seu lugar de vivência.

Para tanto, nos fundamentamos em autores que discutem sobre a educação contextualizada no semiárido, pois percebemos que a grande dificuldade, hoje nas Séries Finais do Ensino Fundamental e Ensino Médio, é desenvolver uma metodologia de trabalho que possa superar os velhos modelos de aulas repetitivas que se utiliza como instrumento de trabalho apenas o livro didático e o quadro negro, pois "a escola está a perder legitimidade aos olhos dos seus alunos, à medida que estes se vão apercebendo do atraso relativamente ao desenvolvimento da sociedade que é suposto ela servir, bem como, dos métodos de aprendizagem retrógrados que continua a adotar" (PAPERT Apud GOMES \& SILVA, 2013, p. 454).

Logo, uma proposta como esta traz diversas contribuições para o desenvolvimento de novas práticas no ensino da matemática, problematizando a realidade de nossos estudantes e oferecendo subsídios para uma aprendizagem significativa. Em assim sendo, os princípios da educação contextualizada se ancoram nas reflexões sobre o cotidiano escolar, tecidos numa dinâmica concebida nas/pelas operações que os estudantes fazem na roça para transpor o conhecimento que aí adquiriram pelas vivências contextuais para a aprendizagem da trigonometria. Trata-se de operações que os estudantes desenvolvem, tanto os que são licenciandos, que executam operações de ensino, como os da escola básica que executam as operações de aprendizagem.

A invenção do cotidiano tem suas raízes numa pesquisa que nasce da interrogação sobre as operações dos usuários, supostamente entregues à passividade e à disciplina. De um lado, análise mostra antes que a relação, sempre social, determina seus termos, e não o inverso. De outro lado, a questão tratada se refere a modos de operação ou esquemas de ação e não diretamente ao sujeito que é o seu autor ou seu veículo. Desta forma, a obra ganha destaque a partir do princípio de ter como objetivo primordial o de explicitar as combinatórias 


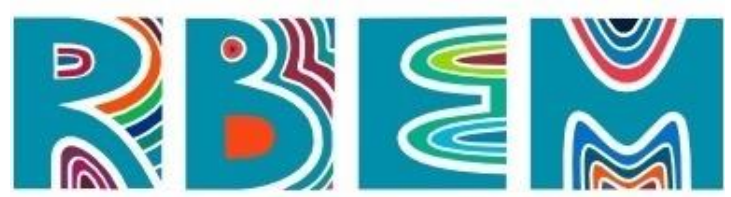

REVISTA BAIANA DE EDUCAÇÃO MATEMÁTICA

de operações que compõem também, sem a pretensão de ser exclusivamente, uma "cultura" e de exumar os modelos de ação característicos dos usuários.

A leitura do texto nos permite entender as dimensões do cotidiano e de suas práticas, vez que fica notória a ideia de que a interrogação sobre as práticas cotidianas foi, a princípio, pensada negativamente pela necessidade por não localizar a diferença cultural nos grupos que portavam a bandeira da "contracultura". Certeua (1994) propõe e investiga os usos que os sujeitos numa relação fabril fazem dos produtos culturais e o que eles "fabricam" a partir de práticas culturais. É dessa lógica que entendemos a concepção criada para as "artes de fazer".

Nessa direção de análise, os produtos culturais usados no cotidiano são apropriados e transformados pelos sujeitos a partir de táticas e modos de fazer que são milenares, mas que dão condições de se produzir novas práticas e novas artes de fazer. Nelas, Certeau (1994) não vê os sujeitos massificados, passivos, disciplinados pela indústria cultural ou por mecanismos de poder. As práticas do cotidiano e as "artes do fazer" apontam para uma caracterização desses sujeitos como sendo produtores, ou no seu discurso, como "outra produção".

O trabalho de Certeau (1994) evidencia que a presença e a circulação de uma representação não sugerem o que ela é para seus usuários. Ressalta que os produtos são utilizados, também, pelos sujeitos que não os fabricam. Dessa condição é que o autor propõe a reflexão de que só então é que se pode analisar a diferença ou a semelhança entre a produção da imagem e a produção secundária que se esconde nos processos de sua utilização.

Assim, as "maneiras de fazer" constituem as mil práticas pelas quais sujeitos, para Certeau (1994) usuários, se reapropriam do espaço organizado pelas técnicas da produção sociocultural. Em sua análise, a "cultura popular" se constitui e se apresenta diferentemente, assim como toda uma literatura chamada "popular". Ela se constitui essencialmente em "artes de fazer" isto ou aquilo, isto é, em consumos combinatórios e utilitários. Nessa lógica, inferimos que a roça é vista como um grande palco em que as "artes do fazer" são ressignificadas entre os sujeitos que lá estão, que se apropriam do cotidiano escolar e desenvolvem distintos modos de conceber culturalmente novas práticas do fazer docente dos modos de aprender matemática pelos conhecimentos ali já produzidos.

As práticas educativas são tomadas como elementos de reflexão para os professores em formação inicial, que em vez de estarem numa lógica de reprodução de técnicas e modos de fazer a docência, inauguram uma cultura reflexiva sobre como os estudantes aprendem 


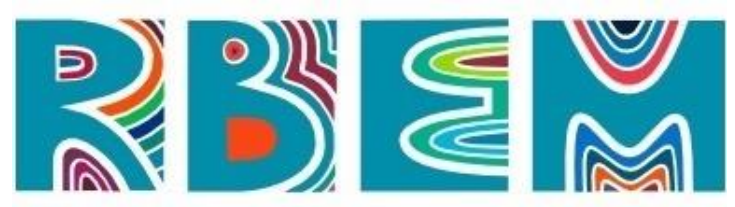

REVISTA BAIANA DE EDUCAÇÃO MATEMÁTICA

inseridos em seus universos experienciais das aprendizagens que logram na roça, vista como um espaço educativo, que a partir do seu cotidiano, gera novas "artes do fazer" tanto para quem aprende como para quem ensina. É aprendizagem sobre a docência e sobre como se ensina matemática contextualmente que figura como elemento combinatório de uma cultura que não prima por mera reprodução de práticas, mas que promove uma reflexão de como se aprende significativamente quando a educação se desenvolve numa perspectiva contextual, tendo o próprio cotidiano como os modos de produção de novas práticas.

Isso se visibilizou nas oficinas, a partir das quais os estudantes de pedagogia perceberam que:

Realizar uma proposta como essa oficina, que nos permite perceber como os estudantes podem aprender a partir do que já existe na roça, com base naquilo que já apresentam como conhecimentos prévios sobre a matemática em seu cotidiano é muito gratificante para nós, que estamos envolvidas numa formação para professores, pois é uma oportunidade de perceber como podemos utilizar aquilo que o cotidiano tem para ensinar conceitos e fórmulas, tornando o ensino da matemática mais prazeroso e de uma forma que seja envolvente. (Relato de Márcia, 2018)

Já os estudantes mostraram que:

Aprender matemática dessa forma que estamos aprendendo aqui na roça, vendo como podemos aplicar os cálculos que aprendemos com as explicações das professoras é muito mais interessante porque a gente consegue aprender e ver como é que se faz na prática, na roça em que moramos. Não fica como se fosse uma coisa de outro mundo que só vamos aprender se decorar fórmulas e fazer aqueles deveres dos livros de matemática. (Relato de Pedro, 2018)

Márcia e Pedro enfatizam como o ensino e a aprendizagem se potencializam quando tecidos numa contextualização pela realidade cotidiana vivenciada. Se para as professoras em formação a oficina gerou modos de apreensão de táticas para o ensino de matemática, para os estudantes é a valorização do saber que eles possuem na lida com a roça o elemento basilar para desenvolver outras aprendizagens. São "artes do fazer" na docência e na lida com a roça que geram possibilidade de ressignificar a matemática e sua contribuição para a vida dos estudantes. 


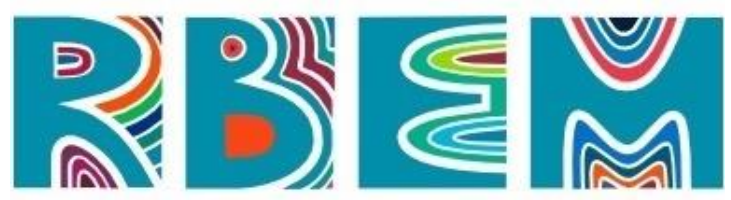

REVISTA BAIANA DE EDUCAÇÃO MATEMÁTICA

As "artes do fazer" na iniciação à docência de licenciandas em pedagogia desvelam o modo como operam aprendizagens na formação inicial de professores, com foco especial nas travessias do ensino de matemática nos anos iniciais do fundamental. Pensar um ensino que favoreça a aprendizagem significativa e contextualizada da matemática, implica, também, em reconhecer a formação de professores no movimento experiencial do cotidiano escolar, em que as insurgências da prática docente se desvelam nas travessias formativas que saem do muro da universidade e acontecem na roça, na escola da vida, de modo a favorecer, conforme Silva e Rios (2018) defendem, as aprendizagens experienciais da docência.

$\mathrm{Na}$ próxima seção, enfocamos alguns resultados sobre o processo de iniciação à docência nas "artes do fazer" de licenciandas de Pedagogia, que buscam nas oficinas criar um cenário de táticas e astúcias para ensinar a jovens da roça uma trigonometria que se ressignifica pelo conhecimento que cada jovem possui e que é capaz de relacionar com o conteúdo que na escola se valoriza.

\section{Artes do fazer dos licenciandos no ensino de matemática}

O modo de fazer o ensino de trigonometria acontecer no espaço rural se singulariza em cada sujeito em formação, dado o contexto de análise que se instaura no cotidiano que nega a ideia de uma repetição, como se o cotidiano fosse uma mesmice. Há uma lógica culturalmente construída de que é necessário desenvolver novos modos de fazer e de conceber a docência por vias de um processo de contextualização da ação docente. Na percepção das professoras em formação inicial, isso se processa pela condição auto avaliativa e reflexiva que estas desenvolvem no processo de ensino, que consideram o saber da criança e de jovens que vivem na roça. É, portanto, no cotidiano da roça que se tem condição de apropriar-se culturalmente das práticas educativas que lá se desenvolvem e que precisam constituir base para outras, que não sejam meramente reprodutivas.

Daí a lógica de ancorar a visão do cotidiano das práticas educativas desenvolvidas na escola aos modos criativos e contemporâneos das "artes de fazer" descritas e analisadas por Certeau (1994) e por Agnes Heller (1997) em outros tempos, contextos, mas numa mesma essência de compreender que o cotidiano não se caracteriza por uma mesmice repetitiva, que não dá lugar a criatividade. 


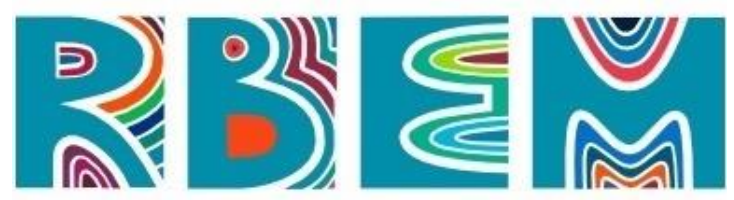

REVISTA BAIANA DE EDUCAÇÃO MATEMÁTICA

Segundo o que preconiza Agnes Heller (1997), o cotidiano não se constitui como mera lógica de reprodução de acontecimentos. Pensar a escola nessa perspectiva significa considerar que as práticas organizativas do trabalho docente não são feitas da mesma forma e só nos muros da escola. Se isso é verdadeiro, será tão verdadeiro o fato de que a formação no cotidiano escolar é constituída por movimentos que não se caracterizam por meras repetições. Assim, cada professor, cada aula, cada prática organizativa é produzida numa lógica de univocidade, pois não se faz uma coisa sempre do mesmo jeito. Em seus depoimentos, as licenciandas revelam como o ensino de matemática pode ser configurado em diferentes aspectos contextuais, além do muro da escola, produzindo acontecências que vêm do significado por cada criança ao poder relacionar o seu saber com o saber escolar.

Nessa perspectiva, as professoras revelaram que as oficinas possibilitaram perceber que as crianças conhecem as noções de área, de perímetro, de cumprimento, de noção de tamanho, ancorado pelos saberes que elas produzem em seu cotidiano na roça. É desse saber que a prática docente se alimenta e se constrói inventivamente e de modo criativo, aproximando tal prática das concepções de inovação de que trataram em seu estudo Alves e Calvalcante (2017). Em seu relato, a professora Clara considera que:

Promover uma oficina numa área rural para ver na prática como podemos aplicar conceitos matemáticos e demonstrar para jovens que moram na roça a utilidade dos conhecimentos matemáticos é de grande importância em nossa formação, principalmente no que diz respeito ao movimento de um ensino de matemática pautado nas propostas de educação contextualizada, por nos oferecer condições de reinventar fazeres na docência, pensando no aproveitamento do conhecimento que cada estudante traz consigo. (Relato de Clara, 2018)

O trabalho com a trigonometria compõe o arsenal de conteúdos trabalhados na unidade, em que é considerada a natureza composicional dos conceitos fundantes que as crianças devem aprender em matemática. Assim, o ensino caminha numa direção de valorar conhecimento, o saber contextual da criança, que tem a oportunidade de perceber como a matemática está articulada ao seu conhecimento diário, cotidiano, com o qual a criança lida na roça, no seio familiar. É dessa condição que se observa a compreensão da criança ao entender que a escola prepara para a vida, para que ela possa lidar com situações com as quais vive. 


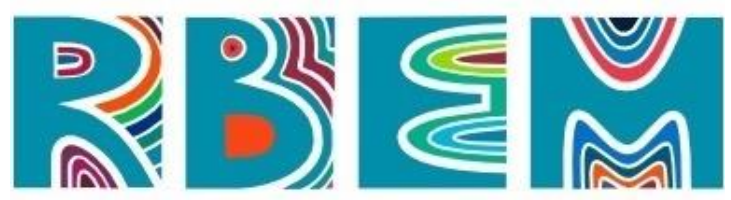

REVISTA BAIANA DE EDUCAÇÃO MATEMÁTICA

Nessa direção, há relatos das crianças afirmando que foi na roça que elas compreenderam o que a professora estava ensinando sobre área, sobre o que significam as formas geométricas que ela conhecia por outra forma, por outros nomes. São os saberes da roça se ressignificando, gerando condições de uma aprendizagem significativa, como defende Ausubel (1982). No relato de Gisele, isso fica evidente quando a jovem, falando do que achou das oficinas expressa que:

Nunca pensei que esses assuntos de trigonometria pudessem ser apresentados para nós de maneira tão interessante e, aqui na roça, através de demonstrações práticas como no exemplo que tivemos para calcular a altura do pé de licurizeiro, formando um triângulo com uma corda amarrada no topo do seu tronco com a sombra que esse tronco fazia. Foi aí que vi a matemática presente em todos os lugares da minha vida. Aprender matemática assim é muito interessante porque a gente sai daquela coisa de ficar na sala de aula com o livro na mão e vai colocar os conceitos em prática. (Relato de Gisele, 2018)

Está na escola, na roça, logo em seu cotidiano, dimensões culturais do processo de ensino e de aprendizagem que são veiculados por professores em formação inicial, que aprendem com as crianças em seu cotidiano na roça e as ensinam a transcender esse conhecimento, levando-as a compreenderem a matemática por outras paragens, mas que não se distanciam das que cada aluno vive em seu cotidiano escolar, sobretudo em seu cotidiano com os trabalhos da roça.

Desta forma, a aprendizagem da docência, e no contexto em voga aqui, a docência para trabalhar as questões do ensino de geometria contextualizado com os saberes da roça, emerge como um processo que se redimensiona a partir das vivências e experiências logradas no cotidiano escolar. Assim o licenciando vai criando novas formas de fazer, que se integram ao modo como cada um compreende e desenvolve os saberes para a docência. Sob o ponto de vista em que o cotidiano é tomado em alguns trabalhos, Alves (2003) nos diz que:

Os trabalhos que se preocupam com o cotidiano da escola e com os diferentes modos culturais aí presentes partem, então, da ideia de que é neste processo que aprendemos e ensinamos a ler, a escrever, a contar, a colocar questões ao mundo que nos cerca, à natureza, à maneira como homens/mulheres se relacionam entre si e com ela, a poetizar a vida, a amar o Outro. Ou seja, ao mesmo tempo que reproduzimos o que aprendemos com as outras gerações e com as linhas sociais determinantes do poder 


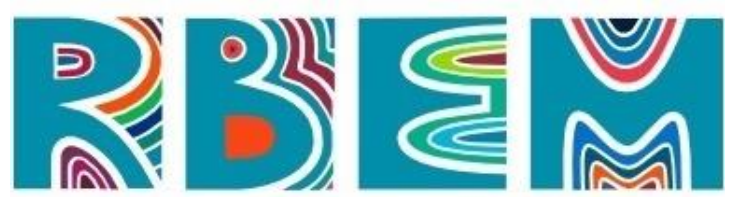

REVISTA BAIANA DE EDUCAÇÃO MATEMÁTICA

hegemônico, vamos criando, todo dia, novas formas de ser e fazer. (ALVES, 2003 p. 66)

Muitas ações são desenvolvidas na escola em seu cotidiano, que culturalmente são entendidas como repetições de certas práticas. Assim, vemos anualmente a realização de jornadas pedagógicas, reunião de pais, festejos comemorativos, atividades culturais, conselhos de classe, reunião de professores, desenvolvimento de projetos educativos, entre outros. A escola numa lógica do senso comum seria comparada a uma dimensão fabril em que produz e reproduz suas ações numa cadência caracterizada por repetições. Mas essa seria uma análise equivocada e negaria a dimensão de se compreender que as subjetividades estão na escola.

As "artes do fazer" se singularizam no cotidiano, do mesmo modo que se singularizam os sujeitos que ali estão. Assim o cotidiano é visto numa heterogeneidade que promove a produção de novas formas de fazer a prática cultural escolar se desenvolver a partir dos modos que cada um se apropria do universo educativo, em especial no estudo em tela do universo de aprendizagem da matemática. Ao sujeito em formação, isso se dá numa visão de empoderamento do saber fazer, que demarca os sentidos para aquilo que se aprende da profissão para a qual está se formando.

Alves \& Garcia (2000) ao tratar de cotidiano, iniciam suas reflexões chamando a atenção dos leitores para o fato de que:

Muito se fala sobre a escola, de fora da escola, de longe da escola, muitas vezes a partir de um absoluto desconhecimento em relação ao que acontece dentro da escola a cada dia, quando os profissionais que nela atuam, os alunos e alunas e seus pais, e a comunidade onde ela está inserida estão cotidianamente interagindo. A escola da qual tantos falam é uma simplificação a partir de um paradigma reducionista que ignora tudo o que se passa e se cria nesse espaço/tempo de aprender e ensinar, de relação de subjetividades, de encontros e desencontros, de socialização. (ALVES \& GARCIA, 2000, p. 7)

Para essas autoras é preciso estar na escola, vivê-la no dia a dia, pois é só lá que se pode ter uma apropriação de formas de aprender e de ensinar, o que se produz no âmbito da socialização e das subjetividades que se constituem pelas relações entre tantos sujeitos que lá vivem. Esclareça-se que a roça é também uma escola, é um espaço não formal, mas de 


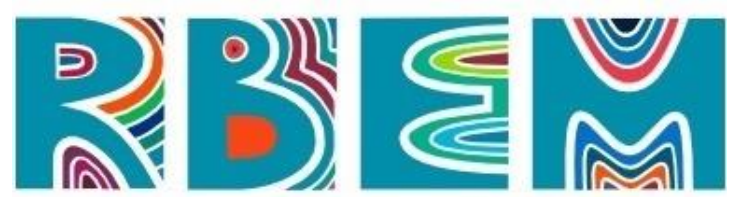

REVISTA BAIANA DE EDUCAÇÃO MATEMÁTICA

aprendizagens significativas do cotidiano, e porque não dizer do cotidiano escolar. Assumir tal posição sobre a escola em sua dinâmica cotidiana, implica entender que a formação do professor precisa acontecer também ancorada na lógica do dia a dia da escola. É sair de uma dimensão dominante de formação que se produz num currículo que pouco vive a escola para além de seus muros para dá a esse mesmo currículo condições de estabelecer uma formação a partir de uma realidade que só pode ser conhecida no interior da escola. Isso diz respeito aos processos de aprendizagem da docência que considera a relação entre os sujeitos da escola como modo de criar novas "artes do fazer" que também se processam na criatividade e na condição de se produzir perspectivas a partir daquelas que são observadas e analisadas no cotidiano da escola.

E é nessas perspectivas que o ensino de trigonometria na roça passa a ter um sentido para quem ensina, como para quem aprende. É válido destacar que a contextualização dos conteúdos matemáticos pode estimular os educandos em meio ao processo de motivação para aprender o que está sendo ensinado, sobretudo se na ação de ensino leva-se em consideração a contextualização como um elemento de experiências particulares que os estudantes vivenciam, como é o caso dos saberes vividos por crianças e jovens da roça. Essa é a perspectiva que Tufano (2001, p. 47) adota ao considerar que a contextualização é um ato particular, é um ato de deslocamento que se produz para vivenciar outras experiências.

Cada autor, escritor, pesquisador ou professor contextualiza de acordo com suas origens, com suas raízes, com seu modo de ver as coisas com muita prudência. E a prudência de professoras em formação inicial lograrem contextualizações do processo de ensino de trigonometria a partir das particularidades vividas pela criança da roça evidencia os deslocamentos que são necessários ser feitos por docentes que estão em franca formação inicial. Isso revelará o modo como cada docente constrói caminhos para gerar contextualizações e ensino significativo, sobretudo na área de matemática que embasa os princípios dos conhecimentos produzidos por uma criança que vive na roça.

A contextualização do conteúdo em si, reflete uma determinada importância face ao cotidiano vivenciado pelos educandos, uma vez que, possibilita que o aluno compreenda que aquilo que se aprende em sala de aula tem aplicação em meio a sua vida prática, na lida da roça e dos modos como vive esse espaço e o contextualiza. Assim, é possível inferir que o 


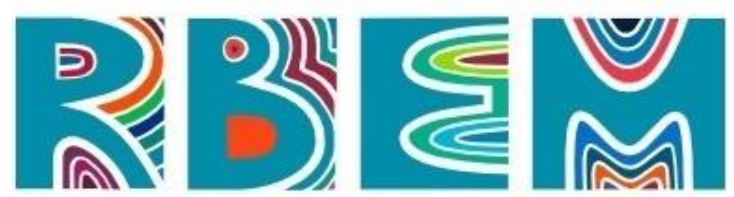

REVISTA BAIANA DE EDUCAÇÃO MATEMÁTICA

ensino contextualizado possibilita os educandos a desenvolverem recursos que os preparam para enfrentar os desafios impostos e existentes no mundo no qual eles (educandos) vivem.

\section{Considerações finais}

O desenvolvimento de propostas que se apoiam nas concepções de educação contextualizada, envolvendo o cotidiano dos estudantes nos proporcionam diversas reflexões sobre como é importante propor aulas que superem um planejamento baseado numa tendência pedagógica não-crítica. Assim sendo, ficou evidente que tal iniciativa ofereceu condições para uma troca de conhecimentos entre os graduandos do curso de Pedagogia e alunos de variadas séries, partindo do pressuposto de que a construção do conhecimento se dá através do diálogo pautado na nossa realidade.

Portanto, a construção de conhecimentos sobre os conceitos de trigonometria e geometria se deram de maneira significativa e dinâmica, potencializando as competências e habilidades dos estudantes envolvidos, trazendo variadas reflexões sobre práticas docentes baseadas na contextualização. Isso nos mostrou condições outras de pensar os fazeres da docência a partir da perspectiva das "artes dos fazeres" que nos provoca a pensar a escola para além de seu espaço físico como possibilidade de ampliar horizontes em relação ao que é apresentado nela.

Assim, como entendem Alves \& Garcia (2000) o presente estudo possibilitou compreender como o cotidiano escolar permite que as teorias aprendidas na formação em licenciatura sejam atualizadas por vivências de contextualizações, tornando o saber do professor produto de construção dos próprios modos de habitar a profissão, tendo em vista as táticas e astúcias necessárias para dar sentido àquilo que se ensina na escola.

As práticas com vivências na roça deram aos licenciandos em perspectivas de buscarem entender situações que provocam a busca de outras explicações teóricas e de outras formas de pensar sobre o que ocorre entre os alunos e os professores, vez que estes têm a função de ensinar e aqueles de aprender. E no caso dos professores em formação, o cotidiano os ajuda a pensar as teorias que aprendem na universidade e a desenvolvê-las a partir daquilo que o conhecimento da escola, da vida, e da roça os faculta. Nesse contexto, o conhecimento de como a escola se organiza e funciona, faz o licenciando desenvolver outra visão sobre esse 


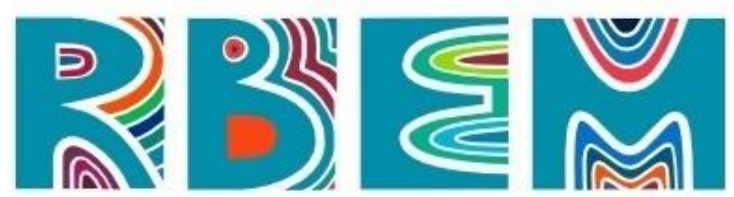

REVISTA BAIANA DE EDUCAÇÃO MATEMÁTICA

espaço, que deixa de ser visto numa ótica antes vista enquanto aluno e passa a ver como professor em formação, mas que instaura em si um processo identitário que o faz tomar consciência da docência no contexto de seu desenvolvimento na escola.

As práticas educativas e cotidianas do ensino de trigonometria na roça são compreendidas pelas professoras em formação na medida em que se apropriam dos sentidos construídos com base em trajetórias e saberes vinculados às experiências que as crianças vão revelando pela vivência na roça e pela compreensão que revelam ter da matemática. Isso sugere que o cotidiano é tomado como um elemento de inspiração e de observação de como as práticas educativas na escola são operacionalizadas numa lógica que evidencia o conhecimento que os sujeitos envolvidos desenvolvem ao perceber a relação da aprendizagem dos alunos com suas próprias trajetórias e representações culturais que fazem do e no cotidiano da escola.

\section{Referências}

ALVES, Nilda e GARCIA, Regina Leite (org.) et al. A Invenção da escola a cada dia. Rio de Janeiro, DP\&A, 2000.

ALVES, Nilda. Tecer conhecimento em rede. In: ALVES, Nilda; GARCIA, Regina L. O Sentido da escola. Rio de Janeiro: DP\&A, 2003, p. 91-100.

ALVES, Rafael Santana; CAVALCANTE, Kellison Lima. Educação contextualizada no ensino de matemática em uma escola no Semiárido de Juazeiro-BA. Revista Semiárido De Visu, v.5, n.1, p. 52-59, Juazeiro-Ba. 2017.

AUSUBEL, David P. A aprendizagem significativa: a teoria de David Ausubel. São Paulo: Moraes, 1982

BRASIL. Pró-letramento. Matemática. Disponível em: <http://portal.mec.gov.br/arquivos/pdf/fasciculo_mat.pdf>. Acesso em: 11 de agos. 2014.

CERTEAU, M. de. A invenção do cotidiano: 1, Artes de fazer. Petrópolis: Vozes, 1994.

GOMES, Antenor, R. e SILVA, Núbia. Imagem e conhecimento: Sentidos moventes, emergências e aprendizagem. Revista de Estudos Universitários, V.39 n.02. Brasil 2013. Disponível em: <http://periodicos.uniso.br/ojs/index.php?journal=reu\&page=issue\&op=view\&path\%5B0\%5 $\mathrm{D}=150 \&$ path\%5B1\%5D=showToc $>$. Acesso em: 09 de jun. 2014. 


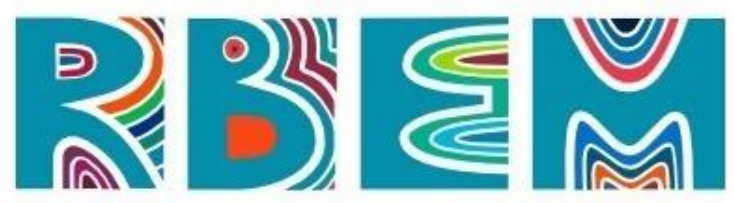

HELLER, Agnes. Sociología de la vida cotidiana. Barcelona: Península, 1977

MORETTO, Vasco Pedro. Prova: um momento privilegiado de estudo, não um acerto de contas. 5 ed. Rio de Janeiro: Dp \& A, 2007.

RIOS, Jane Adriana Vasconcelos Pacheco. Ser ou não ser da roça, eis a questão! Identidades e discursos na escola. Salvador: EDUFBA, 2011.

TUFANO, W. Contextualização. ln: FAZENDA, I. C. Dicionário em Construção: Interdisciplinaridade. São Paulo: Cortez, 2001.

VÁRZEA DO POÇO (BA). Decreto-lei no 09, de 19 de junho de 2015. Plano Municipal de Educação. Arquivo da SME/Várzea do Poço-Ba. 2015.

Artigo submetido em: 16/08/2021

Artigo aceito em: 10/09/2021

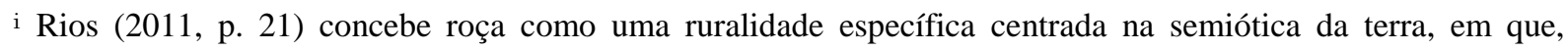
sentidos, itinerários, significados e ressignificações acontecem cotidianamente em caminhos diversos existentes num território configurado por "[...] uma cartografia que passa às margens das roças, que marca passagens, buscas, fronteiras, fazeres de distintas formas".

ii Trata-se de um sítio localizado no município de Várzea do Poço, situado no km 22 da rodovia BA 417 Serrolândia/Várzea do Poço, que serviu como espaço experiencial para desenvolvimento das oficinas.
} 